\title{
PRICING BERMUDAN-TYPE CALL OPTION THROUGH BINOMIAL TREE METHOD
}

\author{
Izma Fahria ${ }^{1^{*}}$ \\ ${ }^{1}$ Universitas Bangka Belitung, Indonesia
}

\begin{abstract}
Bermudan option is a type of option that has characteristics between American option and European option whose its value never exceeds the value of the American option and is never less than the European option. The objective of this research is to calculate Bermudan call option of John Keels Stock through the binomial tree method using statistics software of Matlab R2010a. Assessment of Bermudan type option relates to discrete issues, in which the Bermudan type option has a certain number of times of early exercise specified in the option contract, where such times can only be made at some time prior to the option due date. Precise pricing for Bermudan type option can be obtained by discrete models such as the binomial tree method, a numerical method that is one of the most popular approaches for calculating option prices. This research uses time series data obtained from BNI Financial Update Corner, FEB UGM. The Bermudan call option price calculation will be compared with the calculation of European option pricing and American option price with underlying asset without dividend. The results show that the price of John Keels's Bermudan type call option using the binomial tree method yields the same value as American type call option and European type call option.
\end{abstract}

Keywords: Bermudan Type Option, Binomial Tree Method, Matlab R2010a, Spss 20

\section{INTRODUCTION}

Option is one of the financial derivative products are very popular give the right but not the obligation, to perform at or prior to maturity at a predetermined price. Options become popular because of the price of the option offered on the market are relatively cheap compared to the price or value of the stock, so stock investors can invest with a smaller capital compared to investing directly in the stock price or the actual value.

Options are many sells in the market generally is the American-type option on the grounds of flexibility that can be done before the implementation of the option period runs out or known by the feature early exercise. One type of option to allow exercise early is a Bermudan option. Bermudan option is a type of non-standard American option that has a number of limited time only on certain dates are allowed to exercise early, as has been stated in the contract. Contrary to the American option where feature early exercise can be used until maturity option, Bermudan can be run only on a number of discrete predetermined time.

Rate Bermudan option associated with discrete issues where it is generally recognized that there is no complete solution and must be solved numerically. Three financial economist, John Cox, Stephen Ross, and Mark introduces discrete models such as binomial tree model to solve the problem of complex

* Corresponding author. Email address: Fahriaizma@yahoo.com 
option pricing model (1979). According to Hull (2002), binomial tree is a simple and powerful technique that can be used to solve many problems option pricing.

\section{LITERATURE REVIEW}

Bermudan option is a combination of both the character of the option, the option is European and American options. Adapting the European option properties, Bermudan option can only be exercised at the times specified in the contract and at the time of maturity. But not completely the same as the European option, this option allows the holder to exercise early such American options. American options can be implemented at any time, while the Bermudan option has a limited number of dates in which the option can be exercised annually, quarterly or monthly (Schweizer, 2012).

\section{Binomial Distribution}

The binomial distribution is a discrete probability distribution of the number of successes in $n$ trials yes / no (successful / failed) that are free. Density function of the binomial distribution is

$$
b(x ; n, p)=\left(\begin{array}{l}
n \\
x
\end{array}\right) p^{x} q^{n-x}, x=0,1,2, \ldots, n
$$

$p$ is the probability of success, $q$ is an opportunity to fail, that is $(1-p), x$ is the number of successes in the $n$ repetitions and $n$ is the number of repetitions.

\section{Binomial Tree Model Stock Price}

Cox, Ross \& Rubinstein (1979), assuming the stock price follows the multiplicative binomial process during discrete time periods. An option with maturity $T$ with period $M$ in binomial models, the time until maturity $[0, T]$ partitioned into $M$ sub-intervals of the same. The length of the partition, ie $\Delta t=$ $\frac{T}{M}$. Let $t_{i}=\mathrm{i} \Delta \mathrm{t}$, showing partition points for $i=0,1,2, \ldots, \mathrm{M}$, then for each subinterval $\left(t_{i}, t_{i+} 1\right]$, the asset price is assumed to be constant. If $S_{O}$ is the share price initially at time $t=0$, and at $t=T$ will rise to opportunities $p$ to $S_{o} u$ or going down with odds of $1-p$ to $S_{o} d$, where $u>1$ and $1>d>0$ (Arum.Handini, 2013). Illustration Binomial models for 4 periods $(M=4)$ as in figure 1 . 


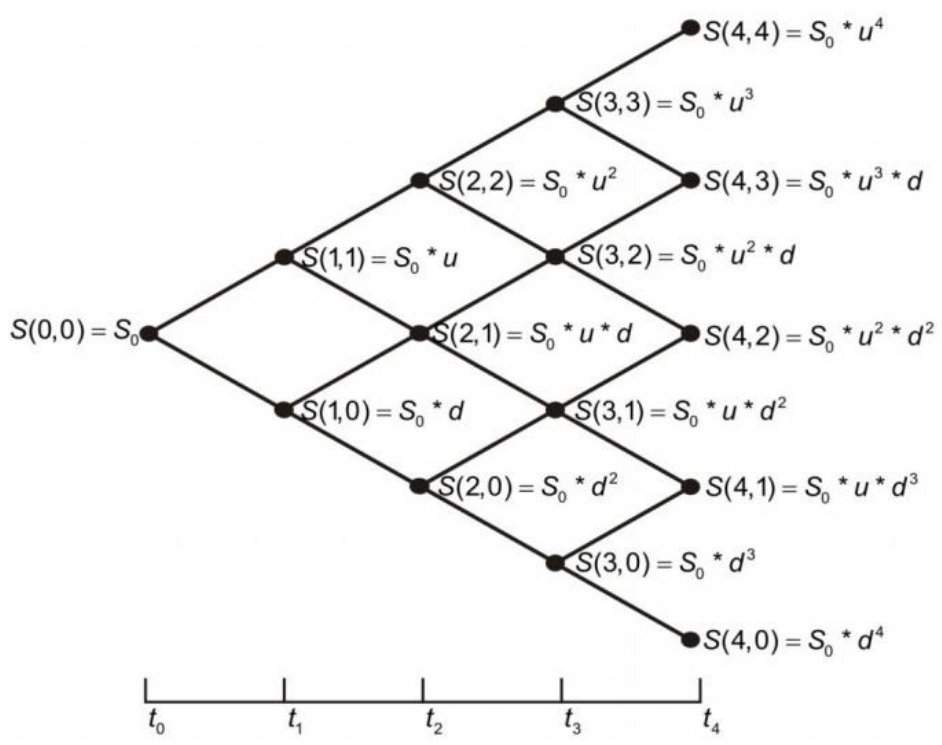

Figure 1 Illustration Binomial Tree Model to 4 periods

Description:

$u=e^{\sigma \sqrt{\Delta t}}, d=e^{-\sigma \sqrt{\Delta t}}$ and $p=\frac{\left(e^{r \Delta t}-d\right)}{u d,}$ where

$\sigma=$ Volatility of stock

$\Delta t=$ length of each period, $\Delta t=\frac{T}{M}$

$M=$ Number of changes in stock prices within $T$ years.

Option pricing model with binomial tree method performed by the Backward method. If known $K$ is the price of an option contract and $\mathrm{S} t$ is the price of the underlying asset at the time of maturity, then the gain callable at the time of maturity is the

$$
f\left(S_{T}\right)=\operatorname{maks}\left(S_{T}-K, 0\right)
$$

\section{Binomial Tree Model for Bermudan Option}

Suppose Bermuda options with expiry $T$ has a number $N$ opportunity to exercise its option, ie $\left\{t_{1}, t_{2,} \ldots, t_{n}=T\right\} \subset[0, T]$,the final condition for Bermuda option equivalent to the final conditions on the American option. If $K$ is the price of the option contract, $C_{B e r} S_{t}$ denotes the value of the Bermuda call option at time $t$, for, $0 \leq t \leq T$ at the price of assets $S$, the final condition for the Bermudan call option can be written as follows $C_{B e r} S_{T}$ payoff $=S_{T}=$ $\left(S_{T}-K\right)^{+}$

Like the American option value calculation, from the final condition $C_{b e r} S_{T}$, the calculation for the value of the options Bermuda with binomial tree method can be done with a backward method. The key is that we value the option at the end of the period for any possible share price. For $t \varepsilon$ $\left\{T_{1}, t_{2}, \ldots, t \quad N\right\}$, the value of $C_{B e r} S_{t}$, can not be less than the value of the payoff;

$$
C_{B e r}\left(S_{t}\right) \geq\left(S_{t}-K\right)^{+} \quad \text { for } t \in\left\{t_{1}, t_{2}, \ldots, t_{N}\right\},
$$

Thus, the model binomial tree for calculation of callable type of Bermuda can be formulated as follows:

For each interval $\left[t_{i}, t_{i+1}\right) \subset[0, T], i=n-1, n-2, \ldots, 1$ and final condition 
$C_{B e r}\left(S_{t_{i+1}}\right)$ calculation $C_{B e r}\left(S_{t}\right), \mathrm{t} \in\left[t_{i}, t_{i+1}\right)$ completed with the following

$$
\left\{\begin{array}{l}
C_{B a r\left(S_{i-1}\right)}=V(i, n)=\operatorname{maks}\left[e^{-r \Delta}\left(p V_{i+1, e+1}+(1-p) V_{i+1, n}\right), C\left(S_{i, n}\right)\right], 0 \leq n \leq i, \text { for } t=t_{i} \\
C_{B \operatorname{ser}\left(S_{i,-1}\right)}=V(i, n)=e^{-r \Delta}\left(p V_{i+1, n+1}+(1-p) V_{i+1, n}\right), 0 \leq n \leq i, \text { for others } t
\end{array}\right.
$$

scheme:

wherein, $t_{i}<t_{i+1} \mid t_{i}, t_{i+1} \in\left\{t_{1}, t_{2}, \ldots, t_{N}\right\}$.

Description:

$S_{i}, n \quad=$ stock price of

$K=$ the option contract price

$r \quad=$ Free interest rate risks

$\Delta t \quad=$ length of each period $(\Delta t=\mathrm{T} / \mathrm{m})$

$\mathrm{T} \quad=$ Period Options

$\mathrm{m} \quad=$ Period stock price change

$C\left(S_{i}, n\right)=$ Function advantage the call option, where:

$C\left(S_{i, n}\right)=\max \left[S_{i, n}-K, 0\right], 0 \leq n \leq i, 0 \leq i \leq T-1$

\section{METHODOLOGY}

\section{The Place, Time and Type Data Research}

This uses secondary data, ie historical data closing prices John Keells shares (JHK) taken on 09 October 2014 to October 9, 2015, and there are 239 in stock prices. Data obtained from one of the financial data providers in the city of Yogyakarta, the BNI Financial Update Corner, FEB. The data were taken in the form of stock prices, the price of the option call Bermuda type, price and options contracts maturing company of John Keels option.

\section{Data Analysis Techniques}

Data analysis in this research is through the method of tree Binomial (Binomial Tree Method) were performed using several steps, namely:

(1) Normality Test Log Return stocks using Kolmogorov-Smirnov to test whether a log returns stock come from populations with normal distribution or not. Furthermore, with $P_{t}$ is the price of an asset in the period to $t$ and $P_{t-1}$ is the price of an asset in the period $(t-1)$, the $\log$ return can be defined as follows:

$$
R_{t}=\log \left(\frac{P_{t}}{P_{t-1}}\right)
$$

(2) Estimates share price volatility determined using the historical volatility that aims to measure the level of risk of a stock. Furthermore, the historical volatility of the stock price can be calculated with the following formula:

$$
\sigma=\sqrt{k \times \frac{\sum_{t=1}^{n}\left(R_{t}-\bar{R}_{t}\right)^{2}}{n-1}}
$$

where $: k=$ number of periods in a year trading 
$R_{t}=\ln \left(\frac{S_{t}}{S_{t-1}}\right)$

$\bar{R}_{t}=\frac{1}{n} \sum_{t=1}^{n} R_{t}$

(3) The risk-free interest rate, the value of risk-free interest rate in this case study is taken from address: the website id.tradingeconomics.com

(4) The calculation of the Bermudan-type call option using the binomial tree model (binomial tree method).

\section{DISCUSSION OF RESULTS}

The stock data used in this study is the historical data on closing price John Keells (JHK). Stock data is taken from 09 October 2014 to October 9, 2015, and there are 239 in stock prices. The share price of John Keells (JHK) was taken on the share price on 20 October 2015 in the amount of 171.25 LKR. The above data will be used in calculating the price of the call option type of Bermudan through binomial tree method. The number of changes in stock prices $n$ or the number of steps selected for the study was 20, 50, 80, 100, 200, 300, 400, 500, $600,700,800,900$ and 1000. The opportunities exercise or time allowed to run option until maturity of one month, the per 2 days, per 4 days and per week.

Historical data on stock prices will be used to calculate the log returns and the estimated historical volatility. Closing stock price movement chart of John Keells (JHK) for one year using Matlab R2010a program can be seen in figure (2).

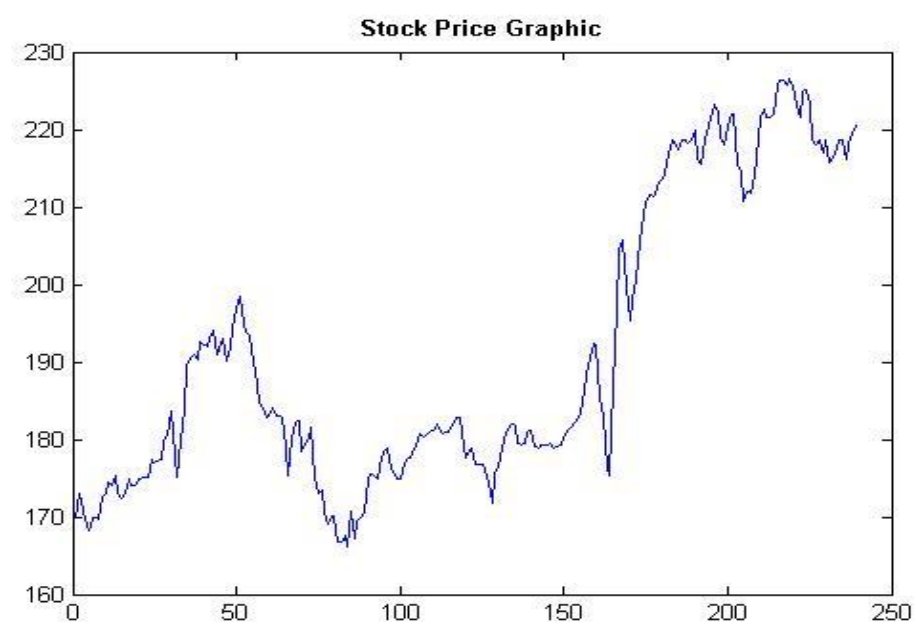

Figure 2 Plot John Keells Stock Price Movement Period October 9, 2014 -

October 9, 2015

Source: Output program Matlab R2010a

\section{Log Return Normality Test}

Normality test was used to test the normality of the log return stock of John Keells (JHK) is Kolmogorov-Smirnov test. Results of output SPSS 20. The results of the output of SPSS 20 is as follows: 
Table 1 Normal Test Logs Return Stock

One-Sample Kolmogorov-Smirnov Test
\begin{tabular}{|ll|l|}
\hline & & $\begin{array}{l}\text { Log_Retu } \\
\mathrm{m}\end{array}$ \\
\hline $\mathrm{N}$ & & 209 \\
& Mean &,- 001487 \\
Normal Parameters, $\mathrm{e}$ & Std. &, 0092747 \\
& Deviation & \\
& Absolute &, 071 \\
Most Extreme & Positive &, 071 \\
Differences & Negative &,- 049 \\
& & 1,023 \\
Kolmogorov-Smimov Z & &, 246 \\
Asymp. Sig. (2-tailed) & & \\
\hline
\end{tabular}

Source: Output Program SPSS 20

Based on output generated the above-obtained $p$-value for lognormality test return John Keells stock is 0.246. The p-value is greater than an alpha of 0.05. It can be concluded that the log return stock of John Keells (JHK) derived from a normally distributed population.

\section{Volatility Estimation}

Estimation results of historical volatility of John Keells shares (JHK) using Matlab R2010a program assistance were obtained for 0,199 or $19.9 \%$.

\section{Risk-Free Interest Rate}

Risk-free interest rate value is taken from an address the website: id.tradingeconomics.com. The value of the risk-free interest rate is the interest rate in Sri-Lanka that is equal to $6 \%$.

\section{Pricing Call Option Bermudan Type}

Using the information gained, the price of shares of John Keells (JHK) on 20 October $2015\left(S_{0)}\right.$ is equal to $171.25 \mathrm{LKR}$, the contract price $(K)$ for 161.87 LKR, risk-free interest rate $(r)$ in Sri-Lanka is 6\%, the volatility $(\sigma)$ of $19.9 \%$ and maturity of the options is November 12, 2015. The purchase option price offered in the market that is equal to $9.47 \mathrm{LKR}$. The results of the comparison calculation of callable Bermudan type with purchase option European and American type using binomial models as follows: 
PRICING BERMUDAN-TYPE CALL OPTION THROUGH BINOMIAL TREE METHOD

Table 2 Option Price Comparison Call Bermuda, Europe and the United States John Keells shares, with the market price $=9.47$ LKR

\begin{tabular}{|c|c|c|c|c|c|}
\hline \multirow[t]{2}{*}{$M$} & \multirow[t]{2}{*}{$\begin{array}{c}\text { European } \\
\text { Call } \\
\text { Option }\end{array}$} & \multicolumn{3}{|c|}{ Bermudan Call Option } & \multirow[t]{2}{*}{$\begin{array}{c}\text { American } \\
\text { Call } \\
\text { Options }\end{array}$} \\
\hline & & per-2 days & $\begin{array}{l}\text { per-4 } \\
\text { days }\end{array}$ & per week & \\
\hline 20 & 10,8822 & 10,8822 & 10,8822 & 10,8822 & 10,8822 \\
\hline 50 & 10,894 & 10,894 & 10,894 & 10,894 & 10,894 \\
\hline 80 & 10,8903 & 10,8903 & 10,8903 & 10,8903 & 10,8903 \\
\hline 100 & 10,8836 & 10,8836 & 10,8836 & 10,8836 & 10,8836 \\
\hline 200 & 10,8844 & 10,8844 & 10,8844 & 10,8844 & 10,8844 \\
\hline 300 & 10,8876 & 10,8876 & 10,8876 & 10,8876 & 10,8876 \\
\hline 400 & 10,8864 & 10,8864 & 10,8864 & 10,8864 & 10,8864 \\
\hline 500 & 10,8853 & 10,8853 & 10,8853 & 10,8853 & 10,8853 \\
\hline 600 & 10,8852 & 10,8852 & 10,8852 & 10,8852 & 10,8852 \\
\hline 700 & 10,8856 & 10,8856 & 10,8856 & 10,8856 & 10,8856 \\
\hline 800 & 10,8862 & 10,8862 & 10,8862 & 10,8862 & 10,8862 \\
\hline 900 & 10,8866 & 10,8866 & 10,8866 & 10,8866 & 10,8866 \\
\hline 1000 & 10,8867 & 10,8867 & 10,8867 & 10,8867 & 10,8867 \\
\hline
\end{tabular}

Source: Output data program Matlab R2010a

From the table 2, that for only one option and one option contract prices, it appears that the results of purchase option price calculation types Bermudan John Keells shares using CRR binomial method produce a value close to the price of purchase options on the market. The value of an option to European or American call purchase option is always greater than its intrinsic value, then the Bermudan call option will be equal to the value of European call option or American option call value. The value of call option itself looks fluctuate with the value of $M$ is increasingly enlarged and will converge to a value for the value of $M$ more. Below is a chart which shows the price movement of Bermudan call option. 


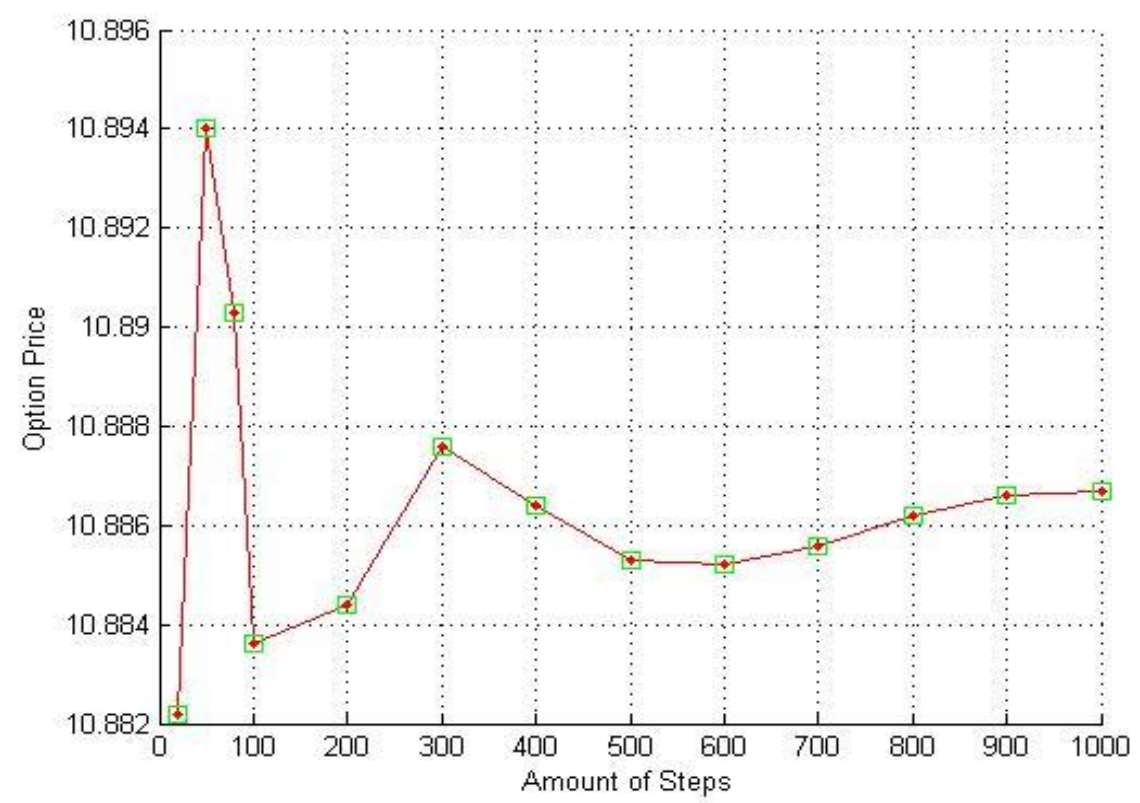

Figure 3 Options Price Movement Buy Bermuda Type Stocks John Keells Sumber: Output program Matlab R2010a

\section{CONCLUSIONS AND RECOMMENDATIONS}

\section{Conclusions}

From the discussion that has been done, it can be concluded that:

1. The pricing of Bermuda options with binomial tree method is influenced by several factors, including the initial stock price of the initial stock price $\left(S_{0}\right)$, price contract $(K)$,risk-free interest rate $(r)$, volatility $(\sigma)$, maturity $(T)$, the number of changes in stock prices $(M)$ and exercise opportunities.

2. Pricing Bermudan call option with the absence of a dividend payment using the binomial method, resulting in the same value when compared with European and American call options. Total number of occasions exercised the Bermudan call option does not affect changes in the value of the option.

\section{Recommendations}

From the discussion in this study, there are several things that can be suggested by the author for further research, among others:

1. Adding other parameters such as the level of dividends to determine how much influence the level of dividends to the value of Bermuda option.

2. Selection of alternative methods for calculating the price of options Bermuda is still possible to obtain more accurate results and approaching the market price.

\section{References}

Cox, J.C., Ross, S.A, \& Rubinstein, M. (1979). Option Pricing: A Simplified Approach. Journal of Financial Economics, 7, 229 - 263.

Higham, J. D. (2004). An introduction To Financial Option Valuation. New York: Cambridge University Press.

Hull, J. C. (2012). Option, Futures and Other Derivatives, Eight Edition. New Jersey: Prentice Hall. 
PRICING BERMUDAN-TYPE CALL OPTION THROUGH BINOMIAL TREE

METHOD

Lyuu, Y. D. (2002). Financial Engineering and Computation: Principles, Mathematics, Algorithms. Cambridge University Press.

Madura, J. (2008). Financial Institutions And Markets, Eight Edition. SouthWestern: Thomson.

Primandari, A. H. (2013). Teknik Ekstrapolasi Richardson Berulang pada Model Binomial Fleksibel Untuk Menentukan Harga Opsi Jual Amerika. [Thesis]. Yogyakarta: Universitas Gadjah Mada, Yogyakarta.

Rosadi, D. (2011). Ekonometrika dan Analisis Runtun Waktu Terapan dengan EViews. Yogyakarta: Andi Yogyakarta.

Schweizer, M. (2002). On Bermudan Option, "Advances in Finance Stochastics Essays in Honour of Dieter Sondermann”, Springer, 257 - 269.

Suharjo, B. (2013). Statistika Terapan Disertai Contoh dengan SPSS. Yogyakarta: Graha Ilmu.

Zhu, Y. L., Wu, X., \& Chern, I.L. (2004). Derivative Securities and Difference Methods, Springer, $376-377$. 